\title{
MESIN PERTANIAN YANG DI GUNAKAN DI DESA TLOGOSADANG, KECAMATAN PACIRAN, KABUPATEN LAMONGAN
}

\author{
Nanda Kusuma Arum, Mahrus Ali \\ Universitas Muhammadiyah Gresik
}

Universitas Merdeka Surabaya

\begin{abstract}
ABSTRAK
Di desa Tlogosadang Kecamatan Paciran Kabupaten Lamongan para petani sudah menggunak mesin dan alat pertanian yang berteknologi, pemanfaatannya bagi para petani didesa sangat menguntung dengan adanya teknologi yang terus berkembang untuk memajukan para petani terutama pada mesin dan alat yang digunakan para petani yang ada di Desa untuk mendukung kinerja para petani yang ada di plosok desa untuk meningkat hasil pertanian untuk meningkat perekonomian di bidang pertanian didesa dengan adanya mesin yang berteknologi para petani lebih efesien waktu dan penghematan biaya untuk mengelolah dalam bidang pertanian.
\end{abstract}

Kata kunci: Mesin dan Alat Pertanian, Desa Tlogosadang, Petani.

\section{PENDAHULUAN}

Indonesia merupakan negara yang kaya akan sumber daya alamnya, terutama dari sektor pertanian. Sektor pertanian merupakan sektor unggulan utama yang harus dikembangkan di negara kita. Hal itu didasarkan pada sejumlah pertimbangan. Pertama, Indonesia mempunyai potensi alam yang dapat dikembangkan sebagai lahan pertaninan, kedua, sebagian besar penduduk Indonesia tinggal di pedesaan yang mayoritas mata pencaharian mereka adalah bertani. Ketiga, perlunya teknologi tinggi dan ilmu pengetahuan yang dirancang untuk mengembangkan pertanian tanpa mengakibatkan kerusakan (Prabowo, 2010).

Namun selama ini sektor pertanian Indonesia belum mampu memenuhi kebutuhan pangan masyarakat Indonesia(Roesli, Heri, \& Rahayu, 2017). Hal tersebut dikarenakan jumlah permintaan kebutuhan pangan yang akan semakin meningkat bersamaan dengan jumlah penduduk indonesia. sehingga pemerintah harus melakukan impor bahan-bahan pangan setiap tahunnya. 
Padi, jagung, kedelai dan gula merupakan empat komoditas pangan pokok yang ditetapkan pemerintah(Lestari, 2017). Produksi padi, jagung, kedelai, dan gula terus meningkat namun dengan laju yang lambat. Dimana sumber utama dari peningkatan produksi adalah perkembangan luas areal panen, bukan perbaikan produktivitas. Peningkatan produksi tersebut masih beresiko mengalami penurunan karena faktor eksternal yang tidak terkontrol seperti faktor iklim dan lain-lain ((Hadi \& Susilowati, 2010).

Peluang Indonesia untuk meningkatkan produksi pangan masih sangat besar. Hal tersebut didasarkan dari segi kekayaan plasma nutfah, ketersediaan lahan dan air, kondisi geografis dan iklim yang kondusif, ketersedian tenaga kerja di pedesaan, dan teknologi ((Hadi \& Susilowati, 2010). Untuk mendukung pemerintah untuk memenuhi kebutuhan pangan masyarakat Indonesia tidak hanya mengenai input dan bentuk luas lahan arae, jenis tanaman yang dibudidayakan, melainkan juga mnegenai kebutuhan alat dan mesin pertanian sebagai faktor pendukung dari usaha tani (Suheiti, 2003).

Peran teknologi disektor pertanian merupakan salah satu upaya menciptakan sistem pertanian yang lebih baik dan efisien. termasuk pula penyediaan alat dan mesin pertanian (Alsintan) yang tepat guna, mendorong petani meningkatkan produktifitas, meningkatkan kualitas lahan dan hasil pertanian serta meningkatkan pendapatan petani. Karena selama ini penggunaan alsintan ditingkat petani masih terbatas, petani pada umumnya lebih memilih cara-cara sederhana dan konvensional dalam melakukan budidaya pertanian(Ali, 2018). Dalam makalah ini kita akan menjelaskan bagaimana pemanfaatan teknologi atau alsintan di tingkat petani di desa Tlogosadang, Kecamatan Paciran, Kabupaten Lamongan.

\section{PEMBAHASAN}

\section{Traktor Roda 4}

pengolahan tanah adalah suatu usaha untuk mempersiapkan lahan bagi pertumbuhan tanaman dengan cara menciptakan kondisi tanah yang siap di tanam. Bebrapa penelitian menyimpulkan masalah pengolahan tanah merupakan masalah yang penting untuk mendapatkan produksi pertanian yang optimal. Kondisi tanah yang baik merupkan salah satu faktor keberhasilan budidaya pertanian, dan untuk mendapatkan kondisi tanah yang baik diperlukan alat-alat pertanian untuk mengolahnya.

Walaupun pengolahan tanah sudah dilakukan manusia sejak dahulu dan mengalami perkembangan baik dari metode dan peralatan yang digunakan. Oleh karena itu perlu adanya 
teknologi baru untuk membantu para petani melakukan pengolahan tanah agar mendapatkan hasil yang baik dan efisien. Salah satu alsintan yang berfungsi untuk pengolahan tanah adalah Traktor roda 4 seperti ditunjukkan pada Gambar 1.

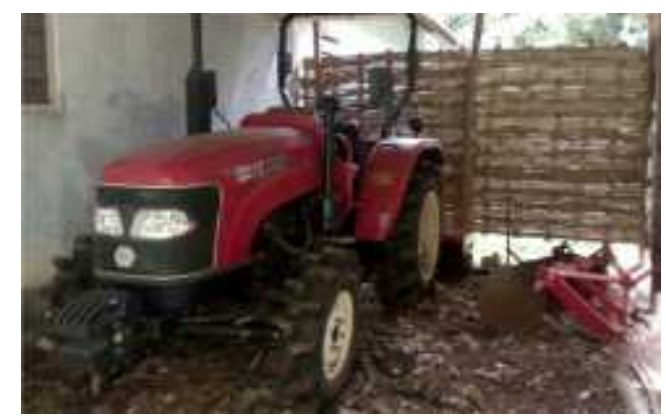

Gambar 1. Traktor Roda 4

Gambar 1. Menunjukkan Traktor roda 4, traktor roda 4 merupakan suatu peralatan yang diciptakan oleh manusia yang sangat bermanfaat untuk membantu meringankan terutama pada kegiatan di bidang pertanian. fungsi utama traktor itu sendiri bila dirangkaikan dengan suatu peralatan tambahan berupa bajak dapat berperan sebagai alat pengolah tanah. Selain itu traktor roda 4 juga berfungsi sebagai tenaga penggerak peralatan mesin-mesin pertanian lainnya melalui power take off (PTO) yang disalurkan ke mesin-mesin yang akan digerakkan.

Gambar 1 menunjukkan bahwa klasifikasi dari traktor roda 4 di atas termasuk dalam Four Wheel Drive with front steering wheel, traktor 4WD yaitu tergolong dalam traktor yang memiliki roda depan lebih kecil dari roda belakang. Traktor tipe ini memiliki traksi yang besar sehingga memiliki tarikan yang kuat.

\section{Traktor Roda 2 (HandTraktor)}

Traktor roda 2 juga merupakan salah satu mesin pengolah tanah yang akhir-akhir ini mulai di gunakan para petani di Indonesia. Hal ini dikarenakan traktor mampu mengatasi masalah petani yaitu dapat mempersingkat waktu persiapan tanah sehingga intensitas tanaman meningkat. Mesin ini juga mulai di gunakan di desa Tlogosadang, Kecamatan paciran, Kabupaten Lamongan. Traktor Roda 2 (HandTraktor) ditunjukkan pada Gambar 2. 


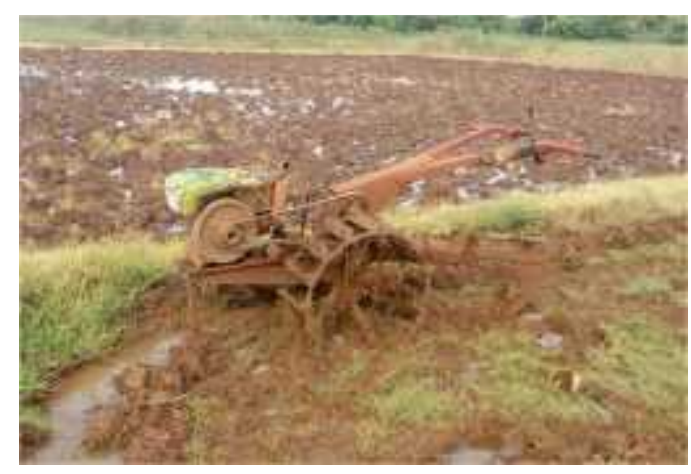

\section{Gamabr 2. Traktor Roda 2 (HandTraktor)}

Gambar 2 menunjukan Traktor tangan (HandTraktor). Traktor tangan merupakan traktor yang hanya mempunyai sebuah poros roda (beroda dua). Traktor ini mempnyai panjang berkisar 1740-2290 mm, lebar berkisar 710-880 mm dan dayanya berkisar 6-10 HP. Traktor tangan (hand tractor) merupakan sumber penggerak dari implemen (peralatan) pertanian.

Traktor tangan biasanya digunakan untuk mengolah tanah. Namun sebenarnya traktor tangan ini merupakan mesin yang serba guna, karena dapat digunakan untuk tenaga penggerak implemen yang lain, seperti : pompa air, alat prosesing, trailer, dan lain-lain. Jenis tenaga penggerak yang sering dipakai adalah motor diesel, tetapi ada juga yang menggunakan motor bensin atau minyak tanah (kerosin). Daya yang dihasilkan kurang dari $12 \mathrm{Hp}$, dengan menggunakan satu silinder.

\section{Mesin Pemipil Jagung}

Selain mesin pengolah tanah traktor roda 4 dan traktor roda 2 di desa Tlogosadang kecamatan Paciran Kabupaten Lamongan. Mesin pemipil jagung juga termasuk alsintan yang sudah di gunakan. Tujuan pemipilan adalah untuk menghindarkan kerusakan,kehilangan, dan memudahkan pengamgkutan serta pengolahan selanjutnya.

Oleh karena itu proses pemipilan dilakukan secara tepat. Di Indonesia terutama didaerah pedesaan, pemipilan harus dilakukan secara tradisional, yaitu dengan tangan. Hasil pemipilan dengan cara tradisional ini kurang efisien dan membutuhkan waktu yang lama. Jadi untuk meningkatkan hasil pemipilan yang tinggi, maka ada berbagai cara dilakukan untuk pemipil jagung. Dimana hasil dari pemipilan jagung tersebut semakin meningkat dan tidak membutuhkan waktu yang lama. Mesin pemipil jagung roda 3 di tunjukkan pada Gambar 3. 


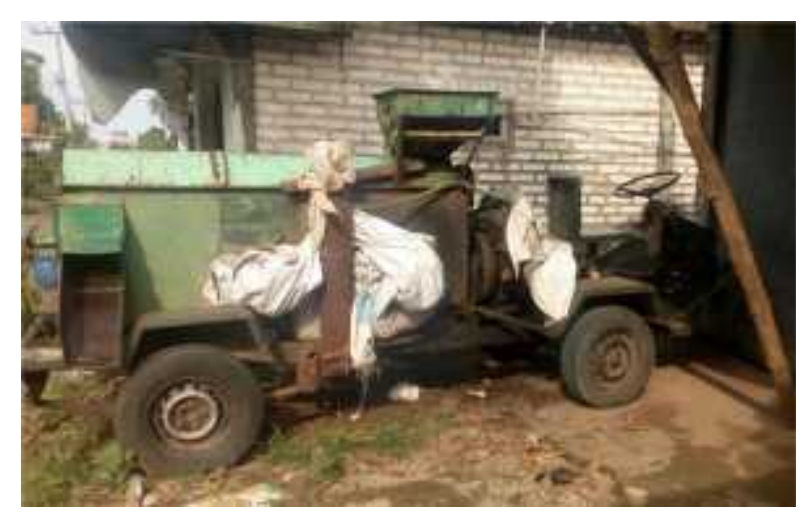

Gambar 3. Mesin Pemipil Jagung

Gambar 3. Menunjukkan mesin pemipil jagung roda 3, Mesin pemipil jagung merupakan mesin yang berfungsi sebagai perontok dan pemisah antara biji jagung dengan tongkol dalam jumlah yang banyak dan secara kontinyu. Mesin ini menggunakan motor bensin sebagai sumber tenaganya, dan menggerakkan mata pemipil agar bisa memipil jagung Mesin pemipil jagung ini untuk memudahkan dan mempercepat proses pemisahan antara tongkol jangung dengan biji jagung setelah proses pengeringan.

Cara kerja dari mesin pemi[il jagung yaitu, jagung dimasukan pada hopper kemudian jagung turun karena getaran mesin ke tabung pemipil dan di rontokan oleh mata pemipil dengan sudut kemiringan $\pm 19^{\circ}$. Mata pemipil akan memindahkan tongkol jagung menuju bagian output. Biji jagung dan tongkol jagung akan berpisah di karenakan bagian tabung bawah di buat saringan. Biji jagung yang bercampur dengan kotoran akan jatuh ke bagian output biji jagung. Sebelum memasuki daerah output biji jagung yang bercampur kotoran akan di hisap oleh blower sehingga biji jagung keluar dalam keadaan bersih alur jagung.

\section{Pengembangan Mesin}

Pengembangan alat mesin pertanian tidak hanya di wilayah yang berpenduduk jarang, tetapi berkembang pula di wilayah yang berpenduduk padat seperti pulau jawa. Pada saat ini pemilikan alat mesin pertanian tidak hanya oleh perkebunan besar, tetapi petani secara perorangan atau perkumpulan petani sudah banyak yang memiliki. Seperti halnya alsintan yang digunakan di daerah Tlogosadang, Paciran, Lamongan sudah cukup baik. Namun perlu adanya pengembangan maupun pengenalan mesin-mesin pertanian yang lain (Rizaldi, 2006).

Pengembangan alat dan mesin pertanian harus selektif, hal tersebut bertujuan agar teknologi yang dikembangkan sesuai dengan sasaran atau tepat guna. Seperti halnya alat penanam, alat pembersih gulma atau alat penyiangan, alat pemupukan(Ali, 2015), dan juga 
pemanenan. Sangat cocok untuk di gunakan di daerah tersebut, namun penggunaannya pun harus didahului denngan bimbingan yang intensif.

\section{KESIMPULAN}

Dari hasil referensi beserta hasil pengamatan langsung, didapatkan kesimpulan bahwa Perlu adanya dukungan pemerintah dalam membantu petani untuk meningkatkan hasil produktifitas pertanian melalui teknologi-teknologi pertanian yang belum banyak di terapkan di desa-desa. Dengan adanya teknologi dalam budidaya pertanian maka akan memudahkan para petani dalam meningkatkan hasil produktifitas tanaman meraka, selain itu akan lebih efisien dalam hal waktu, tenaga, dan biaya.

\section{REFERENCES}

Hadi, P.U., Susilowati, S.H., 2010. Prospek, Masalah dan Strategi Pemenuhan Kebutuhan Pangan Pokok, in: Makalah Dipresentasikan Dalam Seminar Nasional Era Baru Pembangunan Pertanian: Strategi Mengatasi Masalah Pangan, Bioenergi Dan Perubahan Iklim.

Ali, M. (2015). PENGARUH DOSIS PEMUPUKAN NPK TERHADAP PRODUKSI DAN KANDUNGAN CAPSAICIN PADA BUAH TANAMAN CABE RAWIT (Capsicum frutescens L.). JURNAL AGROSAINS: KARYA KREATIF DAN INOVATIF, 2(2), 171-178.

Ali, M. (2018). ALAT DAN MESIN PERTANIAN DI DESA GLURANPLOSO KECAMATAN BENJENG KABUPATEN GRESIK.

Hadi, P. U., \& Susilowati, S. H. (2010). Prospek, Masalah dan Strategi Pemenuhan Kebutuhan Pangan Pokok. In Makalah dipresentasikan dalam Seminar Nasional Era Baru Pembangunan Pertanian: Strategi Mengatasi Masalah Pangan, Bioenergi dan Perubahan Iklim (Vol. 25).

Lestari, V. N. S. (2017). PENTINGNYA MOTIVASI DALAM UPAYA MENINGKATKAN PRODUKTIVITAS KARYAWAN.

Prabowo, R. (2010). Kebijakan Pemerintah dalam Mewujudkan Ketahanan Pangan di Indonesia. Mediagro, 6(2).

Rizaldi, T. (2006). Mesin Peralatan. Departemen Teknologi Pertanian FP-USU, Medan.

Roesli, M., Heri, A., \& Rahayu, S. (2017). Authority of Land Procurement Committee In The Implementation of Compensation For Land Acquisition. YURISDIKSI: Jurnal Wacana Hukum Dan Sains, 10(2), 46-59.

Prabowo, R., 2010. Kebijakan Pemerintah dalam Mewujudkan Ketahanan Pangan di Indonesia. Mediagro 6.

Rizaldi, T., 2006. Mesin Peralatan. Dep. Teknol. Pertan. FP-USU Medan.

Suheiti, K., 2003. Alat dan Mesin Pertanian Tepat Guna Untuk Tanaman Padi dalam Mendukung Program Peningkatan Produksi Beras Nasional (P2BN). https://jambi.litbang.pertanian.go.id/ind/images/PDF/Kiki1.pdf. Diakses 29 Desember 2017. 